\title{
Perceived food and labor equity and school attendance among Ugandan children living in kin care
}

Jini Roby

Brigham Young University - Provo, jini_roby@byu.edu

Stacey Shaw

Brigham Young University - Provo, stacey_shaw@byu.edu

Laurel George

georgelaureld@gmail.com

Follow this and additional works at: https://scholarsarchive.byu.edu/facpub

Part of the Family, Life Course, and Society Commons

\section{Original Publication Citation}

Roby, J.L., Shaw, S.A., \& George, L. (2014). Perceptions of food and labor equity among Ugandan youth living in kin care. International Journal of Social Welfare, 23(2), 205-214.

\section{BYU ScholarsArchive Citation}

Roby, Jini; Shaw, Stacey; and George, Laurel, "Perceived food and labor equity and school attendance among Ugandan children living in kin care" (2013). Faculty Publications. 2934.

https://scholarsarchive. byu.edu/facpub/2934 


\section{Perceived food and labor equity and school attendance among Ugandan children living in kin care}

Roby J.L., Shaw S.A., George L.H. Perceived food and labor equity and school attendance among Ugandan children living in kin care

Emerging research suggests that biological relatedness contributes to differential treatment between children being raised by kin and the biological children in the caregiver's household. This potential concern may be elevated especially when household resources are stretched thin. In this study, 518 Ugandan youth and their caregivers were interviewed individually, examining the association between relatedness and perceived food and work equity, and school attendance. Household income, but not relatedness, was negatively associated with food inequity. However, relatedness was positively associated with perceived disparity in the distribution of work among children living in the household, and with children's school attendance. These findings support and challenge previous findings, raising further research questions and suggesting practice implications.

Key Practitioner Message: - Children in kinship care may be experiencing intrahousehold disparity in the amount of household work they are asked to perform; - Disparity in school attendance between biological and kin children in the same household could have negative implications for the long-term wellbeing of children in kin care; - Programs should be tailored to monitor this type of intrahousehold disparity in treatment.

\section{Jini Lyman Roby', Stacey Anne Shaw², Laurel High George ${ }^{3}$}

1 School of Social Work, Brigham Young University, Provo, UT, USA

2 School of Social Work, Columbia University, New York, NY, USA

${ }^{3}$ Veteran's Administration Services, Salt Lake City, UT, USA

Key words: kinship care, intrahousehold discrimination, orphan care, Uganda, food equity, labor equity, school attendance, Uganda

Jini Lyman Roby, 2166 JFSB - School of Social Work, Brigham Young University, Provo, UT 84602, USA

E-mail: jini.roby@byu.edu

Accepted for publication February 5, 2013
Kinship-based care, the most common form of nonparental care for children around the world (Roby, 2011), is widely utilized in sub-Saharan Africa, both for purposes of training a child or lending support to a relative (purposive or voluntary fostering), and in times of crisis in the parental household (crisis or involuntary fostering) (Bledsoe, 1994; Goody, 1982; Madhaven, 2004; Mathambo \& Gibbs, 2009). Both types of care are typically arranged informally between relatives, with little or no supervision by authorities (Roby, 2011). In the context of more than 13 million children orphaned by the AIDS pandemic in the sub-Saharan region (UNAIDS, 2010), emerging research suggests that the degree of blood relationship between the caregiver and the fostered child may be central to children's experiences in kin care.

Crisis-triggered, culturally obligatory kin care without reciprocity may portend some inherent challenges - relative scarcity of resources, stigma. and risk of maltreatment (Bledsoe, Ewbank, \& Isiugo-Abanihe, 1988; Madhaven, 2004). For example, Castle's (1996) study in Mali found that children in crisis fostering tended to suffer from nutritional disadvantages compared with children receiving voluntary fostering. This concern is sharpened by the fact that crisis kin care has increased dramatically in the past two decades in the sub-Saharan region due to AIDS (Ainsworth \& Filmer, 2006; Beegle, Filmer, Stokes, \& Tiererova, 2009; Biemba, Beard, Brooks, Bresnahan, \& Flynn, 2010; Nyambedha, Wandibba, \& Aagaard-Hansen, 2003). Although in some regions of sub-Saharan Africa the adult HIV infection rates have reached a plateau or fallen (Joint United Nations Programme on HIV/AIDS [UNAIDS], 2009a), orphan numbers continue to climb in most countries due to the lag time between HIV infection and the death of parents (Biemba et al., 2010). While caution is urged to avoid stereotyping crisis in caregiving households (Chirwa, 2002; Meintjes \& Giese, 2006), the overwhelming evidence from the subSaharan region supports the 'social rupture' thesis of kin care (Abebe \& Aase, 2007; Chirwa, 2002), that is, that the orphan crisis has strained the traditional safety 
net of kin care, as limited resources become further stretched (Foster, 2000; Freeman \& Nkomo, 2006; Grant \& Palmiere, 2003; Heymann \& Kidman, 2009).

Extended families absorbing orphans are often among the poorest (Heymann \& Kidman, 2009; Howard et al., 2006; Miller, Gruskin, Subramanian, \& Heymann, 2007). Households caring for orphans are more likely than other parents to suffer financial difficulties, including deficiencies of basic necessities such as food, water, shelter, transportation, or fuel (Heymann, Earle, Rajaraman, Miller, \& Bogen, 2007). Barriers to caregiving and income-earning responsibilities are substantially larger for orphan caregivers than for caregivers without orphans, and their resources are often challenged even further by caring for adults with AIDS (Heymann \& Kidman, 2009). These financial hardships can be severe and impact the adequacy of food (Howard et al., 2006), access to health care (Lindblade, Odhiambo, Rosen, \& DeCock, 2003), education (Ainsworth \& Filmer, 2006; Akresh, 2004), and other measures of wellbeing for both the caregiving adults and the children in their households. The burden of caring for orphans within the kin network has been documented in Uganda during the last two decades (Ntozi, 1997; Roby \& Shaw, 2008), where increasing orphan numbers, rapid population growth, and insufficient government assistance pose challenges to caring for orphans comprising 19 percent of the under-18 population (Christiansen, 2005; Joint United Nations Programme on HIV/AIDS, 2009b; Ministry of Gender, Labour and Social Development, 2004; Wakhweya et al., 2002).

When few resources are available, kin caregivers may exercise unequal distribution of resources between their biological children and other children in their care. This phenomenon, also known as "Hamilton's Rule" (Bishai et al., 2003; Case, Paxson, \& Ableidinger, 2004; Hamilton, 1964ab), has been frequently attributed to evolutionary biology theory which posits that altruistic behavior toward another individual is a function of the closeness of genetic relatedness. Thus, when resources are scarce, a caregiver may allocate them differentially in favor of children who are more closely related to them, at the expense of children who are more distantly related (Bishai et al., 2003; Case, Lin, \& McLanahan, 2000; Case et al., 2004; Oleke, Blystad, Moland, Rekdal, \& Heggenhougen, 2006; Oleke, Blystad, \& Rekdal, 2005).

Notable differences are emerging regarding the amount of food and work requirements, as well as rates of school attendance, as indicia of intrahousehold discrepancy between biological and kin children within the same households. In relation to food, Bledsoe, Ewbank, and Isiugo-Abanihe (1988) found in Sierra Leone that young children in foster care were more malnourished than children living with their mothers, although older children did not show similar disparities. In their study of nearly 27,000 South African households, Case et al. (2000) found that expenditures on "healthy foods" (fruit, vegetables, and milk) were significantly higher when the child was reared by his or her biological mother, whereas less was spent on food for step-, adoptive, or foster children. Orphaned children living with kin may get less food than biological children (Mathambo \& Gibbs, 2009). In Uganda, Bishai et al. (2003) found a clear relationship between the degree of relatedness and child survival, which was largely determined by feeding practices. Oleke et al. (2006) noted in northern Uganda that children living within the extended family often had to work or beg for food.

Differential labor requirements have also been discussed in the sub-Saharan region. In Sierra Leone, Bledsoe et al. (1988) reported significant intrahousehold differences in the degree of punishment between the caregiver's own children, including withholding food while requiring them to perform usual household duties. Qualitative research in Benin by Gestion d'entreprise en culture Africaine (GECA) et al. (2005, reported in USAID \& UNICEF, 2008) suggested that fostered children are often treated differently than the biological children of the head of household, including having to do extra work as well as receiving less food. In that study of 145 children, orphaned and vulnerable children were more than twice as likely as other children to be required to work. On the other hand, Parikh et al. (2007) found in Kwa Zulu Natal, South Africa, that there were no significant differences in education, health, or labor outcomes between biological and kin children in the same household. A more detailed comparison of their study and ours is discussed further in this article.

Differential labor requirements have been noted in Uganda. Oleke et al. (2006, p. 275) described what they found in their 8-month field study in northern Uganda among the Langi tribe of orphaned children living in kin care:

The workload of children aged 7 and above often increased tremendously as they were considered old enough to spend long hours working the fields to make a contribution to the family's subsistence. . . . Some orphaned children were the first to wake up in the homestead in the morning to clean around the compound, and the last to go to bed at night after ensuring that no item was left out in the dark. Rather than being seen as part of the family, the orphans were often treated more like servants recruited from outside for work purposes.

Additionally, in a small $(N=13)$ qualitative study (Harms, Jack, Ssebunnya, \& Kizza, 2010), the authors reported examples describing unequal workload 
distribution and "orphaned youth being treated more harshly compared to other children" (p. 8). Several of the orphaned youth living with kin "alluded to being exploited in their new home situations following the death of their parents" (p. 8). They urged empirical validation of such a possibility and stressed the need for more research focused on the personal perspectives of orphaned youth.

On school attendance, extensive research suggests that children in kin care in sub-Saharan Africa are generally less likely to be attending school than are their peers who live with parents, although they are more likely to go to school than are children living with nonkin (Yamano, Shimamura, \& Sserunkuuma, 2006). A study of orphans and non-orphans in the same households in eight high-HIV prevalence countries in subSaharan Africa found that orphans aged 15 to 17 always had lower school attendance rates than non-orphans (Mishra \& Bignami-Van Assche, 2008). In Uganda, 82 percent of children 10-14 years of age overall were attending school in 2007 (UNGASS Country Progress Report Uganda, 2008), while a Demographic and Health Survey conducted in 2006 showed the ratio of double orphans attending schools as 96 percent of their peers who were living with one or both parents (Joint United Nations Programme on HIV/AIDS, 2009b). Yamano et al. (2006) found that girls aged 15-18 living with nonparent caregivers were less likely to be enrolled in school than were girls living with their parents.

In the present study, we solicited children's perceptions of the amount of food received, the required workload in the household, and school attendance among the children in the household. We hypothesized that we would find reported disparity on all three variables, with fostered children receiving less favorable treatment, and that this perceived disparity would be associated with caregiver relatedness. Although the age range of our sample was 8 to 18 years of age, to avoid confusion and be consistent with definitions provided by the Convention on the Rights of the Child (United Nations, 1989), we refer to all study participants as "children."

\section{Methods}

Sample

A purposive sample of households in and near Kampala, Uganda, was selected as a component of a program evaluation being conducted for Action for Children (AFC), a community-based nongovernmental organization (NGO) providing family preservation services to households at risk of disintegration (Roby \& Shaw, 2008). AFC provides assistance along eight indicators - housing, food security, income generation, children's educational expenses, health and hygiene needs, community involvement, psychosocial support and peer mentoring - all targeting families in extreme poverty, with services geared to keep families intact and moving toward self-sufficiency. Data for this particular report were collected from two subgroups: (i) caregivers $(n=315)$ representing 95 percent of the total participating AFC households; and (ii) children between the ages of 8 and 18 years old $(n=518)$ living in these households. (Younger children were not chosen for this study in order to reduce inaccurate perceptions or reporting.) The final sample of 518 children was reached as follows: Of the 878 children in that age range in the total sample of children, some were away at boarding school or otherwise unavailable. Of those who were physically available, 15 did not complete the interviews either because their caregivers did not give their consent, or the youth chose not to participate. Further after data cleaning, eight child interviews were eliminated due to ambiguities in case identification, resulting in the final sample $(N=518)$.

\section{Procedures}

A cross-sectional design was used for the study and research approval was obtained through the relevant research ethics board prior to data collection. The research team was introduced through AFC to community zone leaders, individuals appointed by the local government councils. These zone leaders initially accompanied the members of the research team to introduce the project and arrange appointments with families. Multilingual local college graduates were trained as interviewers. Caregivers were interviewed at their home and children were interviewed either at home or at an AFC activity at the community center in a private setting. All interviews were conducted in the language chosen by the participant, primarily Luganda. Participating caregivers were given a bar of soap and each child received a pencil as a small token of appreciation for their participation in the study, as recommended by a local research colleague who assisted in supervising project implementation. These data were entered into SPSS version 19 (IBM Corporation, Armonk, NY, USA) for analysis, and later the file was converted to STATA version 12 (StataCorp, College Station, TX, USA) to facilitate multiple imputations in the main analyses.

\section{Measures}

Instruments. Two separate caregiver questionnaires were designed: the first seeking information about the caregiver and the household, and the second information on each child in the caregiver's household ( $n=1,417$, ages 1-19). A third questionnaire sought information from children about their present life and 
future hopes, including the treatment they received in their households. The instruments were developed in English by the researchers in consultation with AFC and a US-based NGO providing funding for the program. The questionnaires were translated into Luganda and Runyoro, the native languages of the participants, and then translated back into English. A local committee provided advisement on cultural accuracy and relevance of the instruments prior to conducting a pilot test of 12 surveys, leading to minor revisions and finalization.

Variables. Data from both caregiver surveys were merged with the child interview data, with variables from all three surveys used in this analysis. Three dependent variables were utilized from the child questionnaire. The first dependent variable, perception of work equity, was measured by the question, "Compared to the other children in your family, do you feel that you work ..." with Likert-type response options $(1=$ much more, $2=$ more, $3=$ same, $4=$ less, $5=$ much less). The second dependent variable, perception of food equity, was assessed using the question, "Compared to the other children in your family, do you feel you get good food ..." $(1=$ much more, $2=$ more, $3=$ same, $4=$ less, $5=$ much less $)$. In order to align the direction of the ranking for these questions, the food equity indicator was reverse coded for analysis so that the higher the number, the greater the perceived preferential treatment, and the lower the number, the greater the perception of being discriminated against within the family. Because of small counts in the extreme response categories, much more and much less, these variables were recoded for use in multinomial logistic regression. The categories much more and more were combined, as were less and much less to create a variable with three categories, with perceived equity as the reference category.

Although all children in the participating households were required to be enrolled in school, and caregivers reported 100 percent school attendance for all children in the sample, because there was variation in the children's reports of school attendance, we examined possible associations between caregiver relatedness and school attendance. Accordingly, the third dependent variable, school attendance, was obtained from the question in the children's questionnaire which asked, "Do you attend school?" ( $1=$ yes, $2=$ no $)$. School attendance was recoded into $0=n o$ and $1=$ yes to facilitate its use in logistic regression analyses.

The key independent variable for this study, the child's relationship to the caregiver, was a categorical variable drawn from the caregiver interview about each child. Caregiver's biological sons and daughters $(n=$ 226) was the reference group, compared with grandchild $(n=205)$ or sibling $(n=15)$, niece or nephew $(n=53)$, and other relative $(n=1)$, step-relative $(n=10)$ or nonrelative $(n=11)$. Due to the small number of sibling caregivers, and given that there was no significance on nonparametric tests in predicting work and food equity between these groups, children who were being cared for by grandparents or siblings were grouped together. Similarly, the relatively low numbers of step-relatives, other relatives, and unrelated caregivers were not significantly different, and were combined. Relationship categories were dummy coded for use in the regression.

We controlled for the amount of financial stress on each household using household income (converted to USD), and employed the log transformation of income to adjust for the non-normal distribution of this variable (skewness $=4.095)$. From the child interviews, we used variables to control for age and gender, as we anticipated that nutritional needs and work expectations might vary by gender and would increase as the child matured. We also controlled for caregiver education level and ratio of nonbiological to biological children in the household, because it is conceivable that household composition might affect perception of food and work equity and school attendance. It was not feasible to control for parental mortality and contact with the child due to missing data.

\section{Analytic approach}

We employed multinomial logistic regression in two separate models to explore whether the caregivers' degree of relatedness to the child was predictive of child perception of equal or disparate treatment in their household with respect to the distribution of work requirements and food. We selected this analysis to examine these main comparisons while accounting for possible differences in outcome variables by income, age, gender, and caregiver education. Using the same control variables, we investigated for possible associations between caregiver relatedness and school attendance, utilizing binomial logistic regression. There were no missing data for the main predictor - child's relatedness to caregiver. Among control variables, about 14 percent of cases were missing for income, a fraction of a percent for school attendance, 1 percent for gender, about 5 percent for caregiver educational attainment, and a fraction of a percent for household ratio of nonbiological to biological children. In order to include these controls and maintain confidence in our multivariate analyses, we used multiple imputation.

\section{Results}

Table 1 displays the results of the descriptive analysis of variables used in the logistic regression. Most of the 
Table 1. Sample characteristics $(N=518)$.

\begin{tabular}{|c|c|c|c|c|}
\hline Variables & $n$ & Mean or \% & SD & Range \\
\hline \multicolumn{5}{|l|}{ Dependent variables } \\
\hline Child's perceived share of work & & & & $1=$ more, $2=$ same, $3=$ less \\
\hline More & 119 & $23.0 \%$ & - & \\
\hline Same & 345 & $66.6 \%$ & - & \\
\hline Less & 54 & $10.4 \%$ & - & \\
\hline Child's perceived share of good food & & & & $1=$ less, 2 = same, $3=$ more \\
\hline Less & 24 & $4.6 \%$ & - & \\
\hline Same & 424 & $81.2 \%$ & - & \\
\hline More & 70 & $13.5 \%$ & - & \\
\hline School attendance & 468 & $89.7 \%$ & & $0=n o, 1=$ yes \\
\hline \multicolumn{5}{|l|}{ Key independent variables } \\
\hline \multicolumn{5}{|l|}{ Child's relationship to caregiver } \\
\hline Biological child (ref) & 226 & $43.4 \%$ & - & $0=n o, 1=y e s$ \\
\hline Grandchild or sibling & 220 & $42.2 \%$ & - & $0=n o, 1=y e s$ \\
\hline Niece or nephew & 53 & $10.2 \%$ & - & $0=$ no, $1=$ yes \\
\hline Other & 22 & $4.2 \%$ & - & $0=n o, 1=y e s$ \\
\hline \multicolumn{5}{|l|}{ Control variables } \\
\hline Income (USD equivalent, annual) & 449 & $\$ 463.00$ & 810.43 & 5 to 5202 \\
\hline Female & 266 & $51.0 \%$ & - & $0=$ male, $1=$ female \\
\hline Age of child & 516 & 12.23 & 2.80 & 8 to 18 years of age \\
\hline Ratio (nonbiological to biological) & 293 & 0.38 & 0.39 & 0 to 1 \\
\hline \multicolumn{5}{|l|}{ Caregiver education level } \\
\hline No education & 84 & $17.0 \%$ & - & $0=n o, 1=y e s$ \\
\hline Some primary & 273 & $55.2 \%$ & - & $0=n o, 1=$ yes \\
\hline Some secondary or postsecondary & 138 & $27.9 \%$ & - & $0=n o, 1=$ yes \\
\hline
\end{tabular}

children interviewed were biological children (43\%) or grandchildren and siblings (42\%), with 10 percent nieces and nephews and 4 percent others. For control variables, gender was nearly equally distributed, with 51 percent female and 49 percent male. The mean age of the children was 12.23 years $(\mathrm{SD}=2.8)$. The annual household income ranged from $\$ 5$ to $\$ 5,202$ USD, with a mean of approximately $\$ 463$ USD (SD = $\$ 810.40 ; \mathrm{Md}=\$ 208.00)$, compared with $\$ 1,700$ USD, which was the mean annual per capita for Uganda for year 2005 (World Fact Book, 2007). The mean ratio of nonbiological to biological children was $0.38(\mathrm{SD}=$ 0.39 ), and caregiver educational levels reflected socioeconomic conditions, with 17 percent of caregivers reporting no formal education, 55 percent some primary education, and 28 percent some secondary or postsecondary education.

For our first key dependent variable - children's perception of how their share of the work compares with that of the other children in the household - two thirds of the children $(66 \%)$ said they did the same amount of work when compared with the other children in the household, 23 percent said they did more work, and about 10 percent reported doing less work. Children were likely to report receiving an equal share of good food (81\%). Approximately 14 percent reported receiving more good food, and a few (about 5\%) reported they received less when compared with others in the household. On the third outcome measure school attendance - more than 10 percent of the children reported that they did not attend school.
Table 2 displays results for the multinomial logistic regression analyses predicting children's perceptions of work and food equity. In our interpretations, for relative risk ratios less than 1.0, we report the inverse value and reverse the outcome categories in order to increase comprehensibility of the results (Osborne, 2006). Relative to biological children, the relative risk for nieces or nephews to perceive that they do more work than other children in the household would be 2.8 times more likely on average $(p<0.01)$, even after controlling for age, gender, income, and household ratio of caregiver's biological children to nonbiological children. However, on average, children living with grandparents and older siblings did not perceive a difference in their work requirements compared with other children in the household. The control variable "age" was also a significant predictor of perceived workload equity; the younger the child, the greater the likelihood of perceiving that he or she did less work than other children in the household. Given a 1-year increase in age, on average, the relative risk of children to perceive their workload as equal to that of the other children would be 1.18 times more likely $(\mathrm{p}<0.01)$.

No association was found between relatedness to caregiver and food inequity. Instead, household income was associated with the child's perception of food inequity. For every 1 percent increase in income, the relative risk of perceiving food distribution as equitable among children in their household would be on average 1.39 times more likely, holding covariates constant $(\mathrm{p}<0.01)$. More generally, an increase in 


\section{Roby et al.}

Table 2. Multinomial logistic regression of caregiver relatedness predicting child perception of work and food equity $(n=517)$.

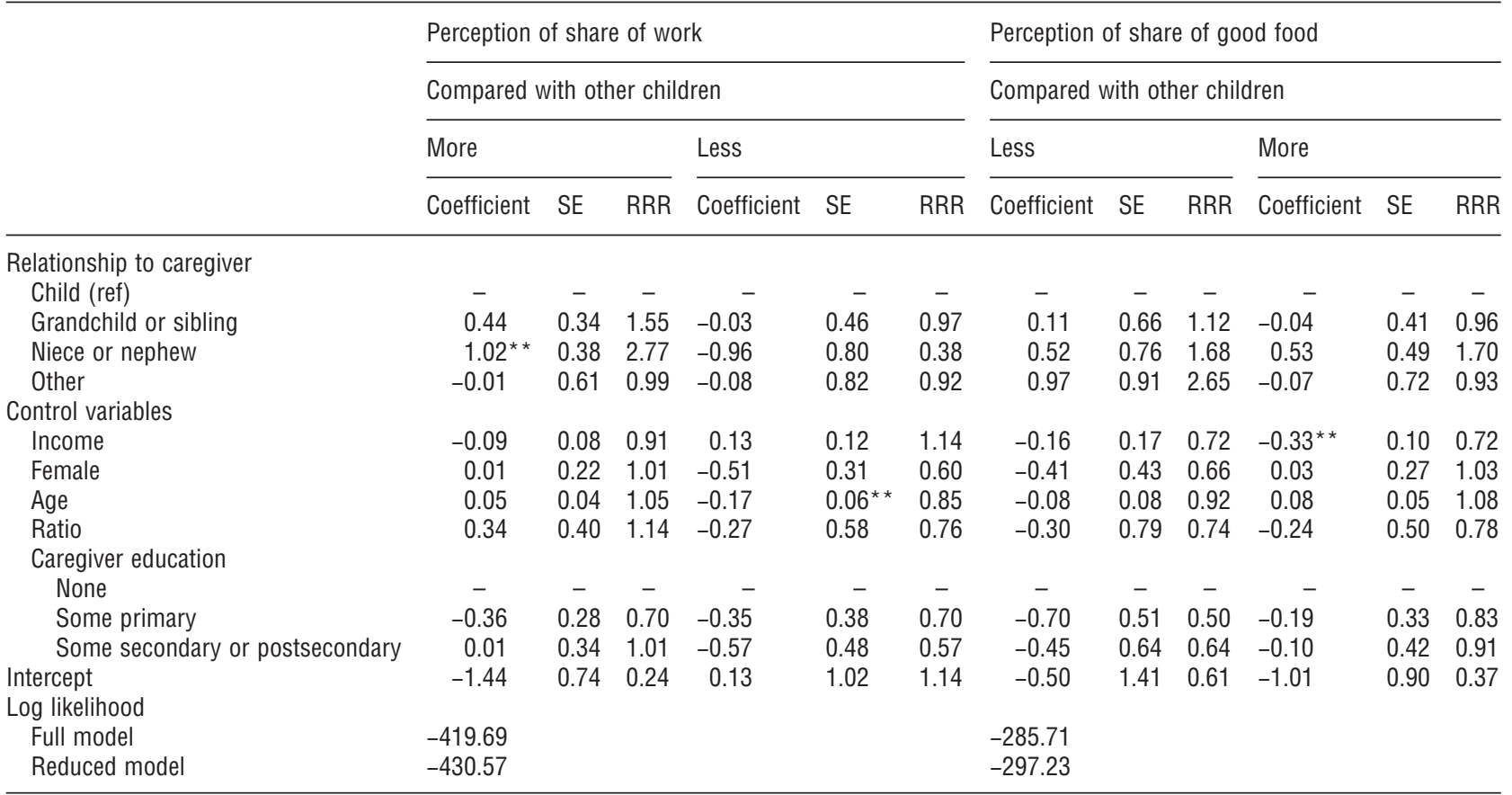

Note: Reduced model statistics omitted from table because there is no difference in significance levels. Base category for outcome variables, child perception of share of work and food is "same." Income is the natural log of USD equivalent funds.

${ }^{*} p<0.05 ;{ }^{* *} p<0.01 ;{ }^{* * *} p<0.001$.

$\mathrm{RRR}$, relative risk ratio; $\mathrm{SE}$, standard error.

Table 3. Logistic regression of caregiver relatedness predicting school attendance $(n=520)$.

\begin{tabular}{|c|c|c|c|c|c|c|}
\hline & Coefficient & SE & $\mathrm{OR}$ & Coef & SE & $\mathrm{OR}$ \\
\hline \multicolumn{7}{|l|}{ Relationship to caregiver } \\
\hline Child (ref) & - & - & - & - & - & - \\
\hline Grandchild or sibling & -0.33 & 0.36 & 1.27 & $0.11^{* *}$ & 0.66 & 0.24 \\
\hline Niece or nephew & -0.53 & 0.61 & 1.40 & $0.52^{*}$ & 0.76 & 0.24 \\
\hline Other & 0.66 & 0.03 & 1.24 & 0.97 & 0.91 & 0.92 \\
\hline \multicolumn{7}{|l|}{ Control variables } \\
\hline Income & & & & -0.16 & 0.17 & 0.99 \\
\hline Female & & & & -0.41 & 0.43 & 1.70 \\
\hline Age & & & & $-0.08^{* * *}$ & 0.08 & 0.74 \\
\hline Household ratio (nonbiological to biological children) & & & & $-0.30^{\star}$ & 0.79 & 0.26 \\
\hline \multicolumn{7}{|l|}{ Caregiver education } \\
\hline None (ref) & & & & - & - & - \\
\hline Some primary & & & & -0.70 & 0.51 & 0.53 \\
\hline Some secondary or postsecondary & & & & -0.45 & 0.64 & 0.73 \\
\hline Intercept & $2.39 * * *$ & 0.24 & 10.89 & $-1.01^{* *}$ & 0.90 & 2325.07 \\
\hline \multicolumn{7}{|l|}{ Log likelihood } \\
\hline Full model & & & & & & -285.71 \\
\hline Reduced model & & & -297.23 & & & \\
\hline
\end{tabular}

Note: Reference category for school attendance is "not attending." Income is natural log of USD equivalent funds.

${ }^{\star} \mathrm{p}<0.05 ;{ }^{* *} \mathrm{p}<0.01 ;{ }^{\star * \star} \mathrm{p}<0.001$

$\mathrm{OR}$, odds ratio; SE, standard error.

income is associated with a higher likelihood of perceiving equity of food distribution among children in the household.

As shown in Table 3, relatedness to caregiver, age, and household ratio of biological to nonbiological children of the caregiver were significant predictors of school attendance. The odds of reporting school attendance would be expected to decrease on average by a factor of 0.24 for nieces and nephews $(p<0.05)$ and for grandchildren and siblings $(\mathrm{p}<0.01)$ compared 
with biological children of caregivers, holding model covariates constant. Because these values are less than 1.0, this relationship may be better understood using the inverse value and reversing the outcome categories (Osborne, 2006). Accordingly, in the present study, the odds of grandchildren or siblings and nieces and nephews reporting that they were not attending school would be 4.17 times greater than the odds of biological children of caregivers. Also, for every year increase in age, we saw on average a decrease by a factor of 0.74 in the odds of reporting school attendance $(p<0.001)$. Interestingly, household composition was also a significant predictor; a higher ratio of nonbiological to biological children was associated with decreased likelihood of school attendance $(\mathrm{OR}=0.26, \mathrm{p}<.05)$.

\section{Discussion}

These findings are both in agreement with and distinguished from previous studies. In general, our study adds to the growing knowledge that grandparents are caring for the majority of children who do not live with their biological parents. In the present study, we saw that 69 percent of the children not living with a parent were residing with their grandparents, compared with only about 18 percent living with aunts and uncles. The study also builds upon previous research that children living with grandparents do not tend to perceive intrahousehold discrimination (Case et al., 2004; Safman, 2004; Subbarao \& Coury, 2003), but also demonstrates that many grandparent-led households experience extreme poverty.

The impact of income on food equity perceptions was consistent with previous studies suggesting that increased income yielded better food intake for members of the household (Duflo, 2000; Haddad, Alderman, Appleton, Song, \& Yohannes, 2003). Related to this linkage, study findings could also suggest how a kin caregiving system can, with support and external assistance (Bronfenbrenner, 1979, 1986), progress from "rupturing" to "adaptive" or even "capable" on the continuum of extended family caregivers constructed by Abebe and Aase (2007). AFC household participants receiving food assistance had significantly $(t(138)=-4.72 ; \mathrm{p}<0.001)$ improved on the food security indicator (Roby \& Shaw, 2008), moving from "very needy" to "needy." Further, because food is not only tangible and reflective of physical wellbeing, but is also symbolic in most cultures (Corr, 2002), food equity may boost physical and psychological wellbeing and a sense of belonging for children in kin care.

The findings on perceived labor requirements add to a relatively new area of research in intrahousehold differentiation between biological and kin children. Data regarding nieces and nephews validated the suspicion by Harms et al. (2010) in Uganda who, through a small but in-depth qualitative study, thought that perhaps children sensed being exploited for labor in their kin care arrangements. Although the sample in our study was larger and employed more quantitative methods, both studies essentially relied on the children's self-reported perceptions.

In contrast, our study's findings differ from those of Parikh et al. (2007) in Kwa Zulu Natal, South Africa. Using a sample of 87 orphaned children living in the same household with 87 comparable non-orphan children, they found that although orphans were at greater risk of doing household chores than were co-resident non-orphans, the differences were not statistically significant. They explained that the short duration in the households (6 months or less), the availability of social grants, and random sampling from schools rather than from poorer areas, may have narrowed the differences. It is unknown how long each of the children in this sample had been in kin care, but some of the families had received some microcredit assistance - usually income-generating work. Finally, our sample was constituted of the poorest families in the community, those receiving support from AFC. Of particular note is the children's report that an increase in income in the sample did not impact the workload disparity.

The differential impact of relatedness on perceived food equity and workload is intriguing. Why is food disparity mitigated by income, when stark differences remain in work requirements regardless of the household's income level? One explanation might be that the consequence of unfair food equity is more tangible and immediately obvious to neighbors and support organizations such as AFC, while the work requirement may be less apparent and/or more culturally tolerated. In addition, there is some suggestion in the literature that in crisis fostering arrangements, the fostered child's labor is deemed to provide the "reciprocity" missing in voluntary arrangements (Oleke et al., 2006; Oleke, Blystad, Rekdal, \& Moland, 2007; World Health Organization, 2011). It is also possible that through income-generating opportunities, adults are away from home more, leaving the bulk of the household chores to the children. The caregiver's lack of time for housework and lack of adult supervision could exacerbate the gap between biological and kin children in the household. In addition, even though some of the AFC households were "better off" than others in terms of income, most of them are still impoverished, and a comparison with kin care households from a wider range of financial abilities may show a narrower margin. It is also possible that kin children have an inherent feeling of nonbelonging as they do not live with their parents, and might be hypersensitive about their status in the family. However, if this were the case, they would have likely reported a sense of food inequity also. 
In any case, while work is a normal part of a household and children are expected to share in the workload appropriate to their age and ability, it is possible that unfair division of work might create a sense of secondclass family membership. Further, when workloads are so heavy that children are less able to concentrate on education, long-term disadvantages can be anticipated. Overly heavy workloads can also rob a child of ageappropriate recreation and leisure, which is an important right of developing children (Lester \& Russell, 2010; United Nations, 1989). In addition, orphaned children who perceive differential workloads may experience work as exploitative (Harms et al., 2010), raising concerns of increased vulnerability to additional hardships (Oleke et al., 2006). Furthermore, the lower rate of school attendance among kin children might be related to an increased workload at home, which could have a long-lasting negative impact in their lives.

\section{Limitations}

There are a number of sampling limitations in this study. While we had a partially built-in control group in that some of the kin children were living in mixed households where both biological and kin children resided, only 10 percent of the children in the sample were nieces and nephews, compared with 42 percent biological children and 43 percent grandchildren or younger siblings of the primary caregiver. Given the imbalance of the groups, generalizability is limited. In addition, some of the kin children may have been residing in households with no biological children of the caregiver, in which case they would have compared themselves with other nonbiological children in the home. Also, while the grandparents and adult sibling relationships are clearly blood relations, it is not known how many of the aunts and uncles were blood relatives to the children (vs. through marriage or custom), diluting application of the evolutionary biology theory to the data. Also, we did not differentiate between maternal and paternal orphans, which could have a significant impact on the outcome (Bishai et al., 2003). Finally, because only some of these families had received varied amounts and length of food and income assistance from AFC, the results are generalizable neither to all kin care households nor to those who receive assistance.

Additional limitations were related to instrumental, procedural, data, and sample issues. For one, the income measure was not ideal because self-reported income may not reflect actual differences in household resources due to differences in the ability to produce food and how microcredit loans were reported. A procedural limitation is that the interviews were written down in English rather than in Luganda, and were not recorded, so there could be interpretation errors and nuances lost. Furthermore, self-reported data can be unreliable, and the subjects' knowledge that the findings would be reported back to the supporting organization in aggregate, even with assurances of confidentiality, might have impacted their responses. Lastly, though ideally we would have been able to discern to which category or categories of relatedness the other children in the household were comparing themselves, the limited size of some groups in the sample prohibited sound statistical results from disaggregating the data by household composition. Also, missing data on measures of maternal and paternal orphanhood did not permit analyses which might have illuminated possible correlations between the children's perception of fair treatment and their orphan status.

\section{Conclusion}

Providing crisis kin care is a daunting task, especially for resource-limited families. Intrahousehold inequity between biological and kin children is likely to be exacerbated when resources are stretched thin. With increased income, the food inequity gap might be reduced. In turn, questions of how household income can be increased, especially for the poorest of families, raise programming challenges. Social transfers, microcredit loans, and old-age pensions are possible avenues to consider.

Requiring kin children to work more than biological children might be a part of the reciprocity equation for struggling kin caregivers, and might reflect embedded cultural values and practice. It is possible that the children themselves might feel an obligation or responsibility to perform additional work in exchange for their care, and take pride in "doing their part." However, such disparity in workloads might not only produce a sense of intrahousehold discrimination, but also impact a child's educational outcomes if sufficient time is not allotted for attending school or completing homework. Additionally, the child's psychological health and sense of wellbeing might be negatively affected if the increased workload is equated with being relegated to a lower status within the family. School attendance might be hindered not only by the increased workload but also by the required costs of supplies and uniforms.

Community programs addressing families providing kinship care have a role in reducing unfair treatment through raising awareness and increasing opportunities for caregivers and children to share their experiences and access support when needed. More in-depth research involving both the caregivers and children in kin care households could shed light on the relevant dynamics that can be targeted in terms of intervention and prevention. 


\section{References}

Abebe, T. \& Aase, A. (2007). Children, AIDS and the politics of orphan care in Ethiopia: The extended family revisited. Social Science \& Medicine, 64, 2058-2069.

Ainsworth, M. \& Filmer, D. (2006). Inequalities in children's schooling: AIDS, orphanhood, poverty and gender. World Development, 30(6), 1099-1128.

Akresh, R. (2004). Adjusting household structure: School enrollment impacts of child fostering in Burkina Faso. Bonn, Germany: IZA.

Beegle, K., Filmer, D., Stokes, A., \& Tiererova, L. (2009). Orphanhood and the living arrangements of children in SubSaharan Africa. Policy Research Working Paper 4889: The World Bank.

Biemba, G., Beard, J., Brooks, B., Bresnahan, M., \& Flynn, D. (2010). The scale, scope and impact of alternative care for OVC in developing countries. Boston: Center for Global Health and Development, Boston University.

Bishai, D., Suliman, E. D., Brahmbhatt, H., Wabwire-Mangen, F., Kigozi, G., Sewankambo, N., . . \& \& Gray, \& R. (2003). Does biological relatedness affect survival? Demographic Research, 8, 261-278. Retrieved from http://www .demographic-research.org/volumes/vol8/9/8-9.pdf

Bledsoe, C. (1994). Children are like young bamboo trees: Potentiality and reproduction in Sub-Saharan Africa. In: K. Lindahl-Kessling, H. Landberg (Eds.), Population, economic development, and the environment (pp. 105-138). Oxford, UK: Oxford University Press.

Bledsoe, C. H., Ewbank, D. C., \& Isiugo-Abanihe, U. C. (1988). The effect of child fostering on feeding practices and access to health services in rural Sierra Leone. Social Science and Medicine, 27(6), 627-636.

Bronfenbrenner, U. (1979). The ecology of human development: Experiments by nature and design. Cambridge, MA: Harvard University Press.

Bronfenbrenner, U. (1986). Ecology of the family as a context for human development: Research perspectives. Developmental Psychology, 22(6), 723-742.doi:10.1037/0012-1649. 22.6.723

Case, A., Lin, I.-F., \& McLanahan, S. (2000). How hungry is the selfish gene? The Economic Journal, 110(466), 781804.

Case, A., Paxson, C., \& Ableidinger, J. (2004). Orphans in Africa: Parental death, poverty, and school enrollment. Demography, 41(3), 483-508. Retrieved from http:// www.jstor.org/stable/1515189

Castle, S. (1996). The current and intergenerational impact of child fostering on children's nutritional status in rural Mali. Human Organization, 55(2), 193-205.

Chirwa, W. C. (2002). Social exclusion and inclusion: Challenges to orphan care in Malawi. Nordic Journal of African Studies, 11(2), 93-103.

Christiansen, C. (2005). Positioning children and institutions of childcare in contemporary Uganda. African Journal of AIDS Research, 4(3), 173-182.doi:10.2989/16085900509490356

Corr, R. (2002). Reciprocity, communion, and sacrifice: Food in Andean ritual and social life. Food and Foodways: Explorations in the History and Culture of Human Nourishment, 10(1-2), 1-25.

Duflo, E. (2000). Child health and household resources in South Africa: Evidence from the Old Age Pension program. The American Economic Review, 90(2), 393-398.

Foster, G. (2000). The capacity of the extended family safety net for orphans in Africa. Psychology, Health and Medicine, 5(1), 55-62. Retrieved from http://www.tandf.co.uk/journals/ alphalist.html

Freeman, M. \& Nkomo, N. (2006). Guardianship of orphans and vulnerable children: A survey of current and prospective South African caregivers. AIDS, 18(4), 302-310.
Goody, E. (1982). Parenthood and social reproduction: Fostering and occupational roles in West Africa. New York: Cambridge University Press.

Grant, M. \& Palmiere, A. (2003). When tea is a luxury: The economic impact of HIV/AIDS in Bulawayo, Zimbabwe. African Studies, 62(2), 213-241.doi:10.1080/00020180 32000148768

Haddad, L., Alderman, H., Appleton, S., Song, L., \& Yohannes, Y. (2003). Reducing child malnutrition: How far does income growth take us? The World Bank Economic Review, 17(1), 107-131.

Hamilton, W. D. (1964a). The genetical evolution of social biology. Journal of Theoretical Biology, 7, 1-16.

Hamilton, W. D. (1964b). The genetical evolution of social biology. Journal of Theoretical Biology, 7, 17-52.

Harms, S., Jack, S., Ssebunnya, J., \& Kizza, R. (2010). The orphaning experience: Descriptions from Ugandan youth who have lost parents to HIV/AIDS. Child and Adolescent Psychiatry and Mental Health, 4(6), 1-10. Retrieved from http://www.capmh.com/content/4/1/6. doi:10.1186/ 1753-2000-4-6

Heymann, J., Earle, A., Rajaraman, C., Miller, C., \& Bogen, K. (2007). Extended family caring for children orphaned by AIDS: Balancing essential work and caregiving in high HIV prevalence nations. AIDS Care, 19(3), 337-345.

Heymann, J. \& Kidman, R. (2009). HIV/AIDS, declining family resources and the community safety net. AIDS Care, 21(S1), 34-42.doi:10.1080/09540120902927593

Howard, B. H., Phillips, C. V., Matinhure, N., Goodman, K. J., McCurdy, S. A., \& Johnson, C. A. (2006). Barriers and incentives to orphan care in a time of AIDS and economic crisis: A cross-sectional survey of caregivers in rural Zimbabwe. $B M C$ Public Health, 6(1), 27-38.doi:10.1186/1471-2458-6-27

Joint United Nations Programme on HIV/AIDS. (2009a). AIDS Epidemic Update December 2009. Retrieved from: http:// whqlibdoc.who.int/unaids/2009/9789291738328_eng.pdf

Joint United Nations Programme on HIV/AIDS. (2009b) Children and AIDS: Fourth Stocktaking Report. ISBN: 978 92,806 4474-6. Retrieved from http://www.unicef.org/ publications/index $51902 . \mathrm{html}$

Lester, S. \& Russell, W. (2010). Children's right to play: An examination of the importance of play in the lives of children worldwide. The Hague, The Netherlands: Bernard van Leer Foundation.

Lindblade, K. A., Odhiambo, F., Rosen, D. H., \& DeCock, K. M. (2003). Health and nutritional status of orphans $<6$ years old cared for by relatives in western Kenya. Tropical Medicine and International Health, 8(1), 67-72.

Madhaven, S. (2004). Fosterage patterns in the age of AIDS: Continuity and change. Social Science \& Medicine, 58, 1443-1454.

Mathambo, V. \& Gibbs, A. (2009). Extended family childcare arrangements in a context of AIDS: Collapse or adaptation? AIDS Care, 21(Suppl. 1), 22-27.doi:10.1080/09540120902 942949

Meintjes, H. \& Giese, S. (2006). Spinning the epidemic: The making of mythologies of orphanhood in the context of AIDS. Childhood, 13(3), 407-430. Paper presented at the International conference on Children and Youth in Emerging and Transforming Societies, 29 June-3rd July, 2005, Oslo.

Miller, C. M., Gruskin, S., Subramanian, S. V., \& Heymann, J. (2007). Examining the situation of orphans during the AIDS epidemic. Social Science and Medicine, 64, 2476-2486.

Ministry of Gender, Labour and Social Development. (2004). National orphans and other vulnerable children policy: Hope never runs dry. Kampala, Uganda: Ministry of Gender, Labour, and Social Development. Retrieved from http:// www.worlded.org/docs/Publications/hiv/ove_policy.pdf

Mishra, V. \& Bignami-Van Assche, S. (2008). Orphans and vulnerable children in high-prevalence countries in sub-Saharan 


\section{Roby et al.}

Africa. DHS Analytical Studies, 15. Prepared for USAID, Washington, D.C.

Ntozi, J. P. M. (1997). Effects of AIDS on children: The problem of orphans in Uganda. Health Transition Review, 7(Suppl.), 23-40.

Nyambedha, E. O., Wandibba, S., \& Aagaard-Hansen, J. (2003). Changing patterns of orphan care due to the HIV epidemic in western Kenya. Social Science \& Medicine, 57, 301-311.

Oleke, C., Blystad, A., Moland, K. M., Rekdal, O. B., \& Heggenhougen, K. (2006). The varying vulnerability of orphans: The case of the Langi, northern Uganda. Childhood, 13(2), 267-284.doi:10.1177/0907568206062943

Oleke, C., Blystad, A., \& Rekdal, O. (2005). "When the obvious brother is not there": Political and cultural contexts of the orphan challenge in northern Uganda. Social Science \& Medicine, 61(12), 2628-2638.

Oleke, C., Blystad, A., Rekdal, O. B., \& Moland, K. M. (2007). Experiences of orphan care in Amach, Uganda: Assessing policy implications. Journal of Social Aspects of HIV/AIDS, 4(1), 532-543. Retrieved from http://www .ajol.info/index.php/saharaj/article/viewFile/30120/22764

Osborne, J. W. (2006). Bringing balance and technical accuracy to reporting odds ratios and the results of logistic regression analysis. Practical Assessment, Research \& Evaluation, 11(7), 1-6. Retrieved from: http://pareonline.net/pdf/ v11n7.pdf

Parikh, A., DeSilva, M. B., Cakwe, M., Quinlan, T., Simon, J. L., Skalicky, A., \& Zhuwau, T. (2007). Exploring the Cinderella myth: Intrahousehold differences in child wellbeing between orphans and non-orphans in Amajuba District, South Africa. AIDS, 21(Suppl. 7), S95-S103.

Roby, J. (2011). Discussion paper on children in informal care. Commissioned by UNICEF New York. Retrieved from: http://www.unicef.org/protection/Informal_care_discussion paper_final.pdf

Roby, J. L. \& Shaw, S. A. (2008). An evaluation of a communitybased orphan care program in Uganda. Families in Society, 89(1), 119-128.
Safman, R. M. (2004). Assessing the impact of orphanhood on Thai children affected by AIDS and their caregivers. AIDS Care, 16(1), 11-19.

Subbarao, K. \& Coury, D. (2003). Orphans in sub-Saharan Countries: A Framework for public action. World Bank Africa Region (Human Development) and Human Development Network (Social Protection).

UNAIDS. (2010). Global Report on the Global AIDS Epidemic. Retrieved from http://www.unaids.org/documents/20101123 globalreport_em.pdf

UNGASS Country Progress Report Uganda. (2008). Kampla: Uganda AIDS Commission. Retrieved from http:// data.unaids.org/pub/Report/2008/uganda_2008_country _progress_report_en.pdf

United Nations. (1989). Convention on the Rights of the Child. Retrieved from http://www2.ohchr.org/english/law/crc.htm

USAID \& UNICEF. (2008). The evidence base for programming for children affected by HIV/AIDS in low prevalence and concentrated epidemic countries. New York: UNICEF.

Wakhweya, A., Kateregga, C., Konde-Lule, J., Mukyala, R., Sabin, L., Williams, M., \& Heggenhougen, H. K. (2002). Situation analysis of orphans in Uganda: Orphans and their households: Caring for the future today. Kampala: Ministry of Gender, Labour and Social Development.

World Fact Book. (2007). Uganda. Retrieved from https:// www.cia.gov/library/publications/the-world-factbook/geos/ ug.html

World Health Organization. (2011). Child-fosterage promises and trafficking in children for domestic work in Nigeria: issues and implications for policy. Retrieved from http:// whqlibdoc.who.int/hq/2011/WHO_RHR_HRP_11.05_eng .pdf

Yamano, T., Shimamura, Y., \& Sserunkuuma, D. (2006). Living arrangements and schooling of orphaned children and adolescents in Uganda. Economic Development and Cultural Change, 54(4), 833-856. 